\title{
Papilloedema delaying diagnosis of Wernicke's encephalopathy in a comatose patient
}

\author{
Colin J. Mumford
}

Department of Neurology, University Hospital, Queen's Medical Centre, Nottingham NG7 2UH, UK.

\begin{abstract}
Summary: A case of acute Wernicke's encephalopathy due to hyperemesis gravidarum is described. Florid bilateral papilloedema was present, resulting in diagnostic uncertainty and delay in treatment. Attention is drawn to the rare occurrence of papilloedema in Wernicke's encephalopathy, and possible underlying mechanisms for this physical finding are considered.
\end{abstract}

\section{Introduction}

Wernicke's encephalopathy is usually associated with chronic alcohol abuse. ${ }^{1}$ It may also occur in other clinical contexts including hyperemesis gravidarum, ${ }^{2-4}$ inadequate diet due to malabsorption, forced or self-imposed starvation, anorexia and prolonged intravenous feeding. ${ }^{5-7}$

I report a case of severe Wernicke's encephalopathy where the presence of papilloedema caused potentially serious delay in diagnosis.

\section{Case report}

A 24 year old housewife presented to an ante-natal clinic in the 16th week of her second pregnancy. A previous pregnancy had ended with an intra-uterine fetal death (IUFD) at 26 weeks gestation for which no cause was found.

During the current pregnancy she had begun vomiting in the 8th week of pregnancy, and this continued without remission. At presentation she complained of nausea, difficulty focussing her eyes and a band of numbness around her waist.

Examination on admission showed her to be mentally withdrawn with slow speech. She was clinically dehydrated and apyrexial, blood pressure 125/ $80 \mathrm{mmHg}$. The uterus was compatible with 16 weeks' gestation. No focal neurological signs were detected. Rehydration was commenced with intravenous $5 \%$ dextrose and dextrose/saline solution.

The following day she was seen by a senior medical registrar. There was no change in her conscious level but she was noted to be ataxic. Vertical and horizontal

Correspondence: C.J. Mumford, B.Med Sci., M.R.C.P., UK Accepted: 18 January 1989 nystagmus was present. She was unable to abduct either eye. Fundoscopy showed marked bilateral papilloedema with capillary dilatation and peripapillary flame haemorrhages. A working diagnosis of a cerebral space occupying lesion was made. She was transferred to the local neurological centre for investigation. On arrival she was unresponsive to commands, produced no comprehensible speech, and showed no eye opening, even with painful stimuli. She had received 1 litre of $5 \%$ dextrose and 2.5 litres of dextrose/saline via intravenous infusion in the 36 hours prior to neurological review.

Investigations showed a low serum potassium, $2.7 \mathrm{mmol} / 1$ (normal $3.5-5.3 \mathrm{mmol} / \mathrm{l}$ ), and low urea, $0.6 \mathrm{mmol} / \mathrm{l}$ (normal $2.0-6.5 \mathrm{mmol} / \mathrm{l}$ ). Bicarbonate was $19 \mathrm{mmol} / \mathrm{l}$ (normal 24-32). Other electrolytes, creatinine and full blood count were within normal limits. Alanine aminotransferase was elevated, $153 \mathrm{IU} / 1$ (normal 0-40 IU/1). Other tests of liver function were in the normal range. Urinalysis showed $4+$ ketonuria. Blood and urine cultures were sterile. A computerized tomography (CT) brain scan with intravenous contrast was normal. An electroencephalogram showed considerable slow activity, most marked in the right temporal area. Lumbar puncture showed an opening pressure of $19 \mathrm{~cm}$ cerebrospinal fluid (CSF), the CSF protein and glucose contents were normal as was microscopy, and culture was negative.

A clinical diagnosis of Wernicke's encephalopathy was then made, and treatment with high dose intravenous thiamine was commenced. The diagnosis was subsequently confirmed by a reduced red cell transketolase of $0.08 \mathrm{IU} / \mathrm{gHb}$ (normal $0.59-1.06 \mathrm{IU} / \mathrm{gHb}$ ) with a thiamine pyrophosphate effect of $355 \%$ (normal 2-20\%). Significant clinical improvement occurred within 6 hours.

The Fellowship of Postgraduate Medicine, 1989 
A bizarre aspect to the history was revealed following recovery. It was a firmly held belief in the patient's family that symptoms such as nausea and visual disturbance were the legacy of an allergy to the chloride ion in food and tap water. At the onset of the patient's symptoms of hyperemesis gravidarum she had immediately been placed on a strict exclusion diet by her overprotective mother. For eight weeks prior to presentation her diet was composed solely of bottled spring water together with bananas and small quantities of meat juices. Strict dietary advice was given to both patient and mother before discharge.

On out-patient review 5 weeks after admission the patient remained well with no residual neurological signs. Visual acuity was $6 / 5$ bilaterally, visual fields were full with no blind spot enlargement. The optic discs were normal. Red cell transketolase was $0.78 \mathrm{IU} /$ $\mathrm{gHb}$ with a thiamine pyrophosphate effect of $6.8 \%$. Alanine aminotransferase was $8 \mathrm{IU} / \mathrm{l}$. The pregnancy was progressing normally.

\section{Discussion}

Wernicke's encephalopathy is a potentially fatal nutritional disorder due to thiamine deficiency. The thiamine deficiency produced by hyperemesis gravidarum in the present case was worsened by the adoption of a wholly inappropriate diet in a misguided effort to ameliorate the vomiting. Intravenous sugarcontaining solutions may also reduce already depleted thiamine stores to negligible levels, and are contraindicated in Wernicke's encephalopathy. ${ }^{6.8}$ The administration of such fluids in the present case will have aggravated the patient's condition. Clinical improvement was rapid following the administration of parenteral thiamine.

Frank papilloedema is rare in Wernicke's encephalopathy. It is not described as an associated physical sign in a recent review of a large series of patients, ${ }^{9}$ and is recorded very infrequently in other series. ${ }^{1}$ In an analysis of ocular signs in Wernicke's encephalopathy performed on a series of 52 Japanese prisoners-of-war, only two cases $(4 \%)$ were found to have papilloedema. ${ }^{10}$ Retinal haemorrhages without papilloedema are probably a more frequent manifestation, " but in an exhaustive study of 245 patients in Boston, small retinal haemorrhages were an associated finding in only six cases $(2 \%)$. No cases were seen with papilloedema or other abnormalities of the optic disc. ${ }^{12}$

The mechanism of production of papilloedema in Wernicke's encephalopathy is unclear. None of the generally accepted theories regarding generation of papilloedema is readily applicable. In the present case there was at no stage additional objective evidence for raised intracranial pressure despite unequivocal papil- loedema. A contrast-enhanced CT scan was norma with no evidence of brain swelling, and a lumbas? puncture showed a normal opening pressure Similarly, there was no elevation of CSF protei content, a factor which has been postulated in the development of some cases of papilloedema, partic ularly in cases of the Guillain-Barré syndrome. ${ }^{13} \stackrel{5}{9}$

Some other mechanism causing an increase it pressure around the optic nerves must be presen giving rise to oedema of the nerve heads, which is itse presumably consequent on nerve fibre swelling an $\$$ obstruction of axoplasmic flow. ${ }^{14}$ Disc hyperaemif and retinal haemorrhages are generally considered to be secondary to optic disc oedema. ${ }^{15}$ The most straightforward explanation for such nerve fibre swelling it: the present context would be to postulate a Wernickes encephalopathy-associated optic neuritis or neuropathy? analogous to the nutritional retrobulbar neuropathie such as those reported in pellagra and associated wit/ tobacco. ${ }^{16}$ However, if this is the case, then the degree of disc swelling, venous congestion and extent of peri-papillary haemorrhage, coupled with relative preservation of visual acuity and full visual fields on recovery would be remarkable.

It is interesting to speculate an alternative theory regarding the few cases of Wernicke's encephalopath where papilloedema and/or retinal haemorrhages are seen. These findings might result from the occurrence्छ of the typical neuropathological features of vero nicke's encephalopathy, characterized by necrosis. of both nerve cells and myelinated structures, and suloes quent oedema, within the optic nerves themselvess Many of the common clinical findings in this condition are explained on the basis of such neuropathologicas correlation. ${ }^{1}$ Overall, no satisfactory explanation is presently available to explain this unusual physica $\vec{D}$ finding in this condition.

The present case provides clear illustration of the principle that all patients with a poor nutritional status. and impaired conscious level should be treated wit? high dose parenteral thiamine, whether the typicat. features of Wernicke's encephalopathy are present oํㅗำ not. Papilloedema is a rare clinical finding in this condition. If present, this physical sign may stronglo suggest an intracranial tumour, but the presence of papilloedema must not delay the administration of thiamine.

\section{Acknowledgements}

I am grateful to Dr A.M. Whiteley and Mr C.N. Bain for permission to report this case. 


\section{References}

1. Reuler, J.B., Girard, D.E. \& Cooney, T.G. Current concepts. Wernicke's encephalopathy. $N$ Engl J Med 1985, 312: 1035-1039.

2. Nightingale, S., Bates, D., Heath, P.D. \& Barron, S.L. Wernicke's encephalopathy in hyperemesis gravidarum. Postgrad Med J 1982, 58: 558-559.

3. Wood, P., Murray, A., Sinha, B., Godley, M. \& Goldsmith, H.J. Wernicke's encephalopathy induced by hyperemesis gravidarum. Case reports. $\mathrm{Br} J$ Obstet Gynaecol 1983, 90: 583-586.

4. Lavin, P.J.M., Smith, D., Kori, S.H. \& Ellenburger, C. JR. Wernicke's encephalopathy: a predictable complication of hyperemesis gravidarum. Obstet Gynecol 1983, 62 (Suppl): 13s-15s.

5. Handler, C.E. \& Perkin, G.D. Anorexia nervosa and Wernicke's encephalopathy: an underlying assocation. Lancet 1982, ii: $771-772$.

6. Pentland, B. \& Mawdsley, C. Wernicke's encephalopathy following 'hunger strike'. Postgrad Med J 1982, 58: 427-428.

7. Devathsan, G. \& Koh, C. Wernicke's encephalopathy in prolonged fasting. Lancet 1982, ii: 1108-1109.

8. Wallis, W.E., Willoughby, E. \& Baker, P. Coma in the Wernicke-Korsakoff syndrome. Lancet 1978, ii: 400.
9. Harper, C.G., Giles, M. \& Finlay-Jones, R. Clinical signs in the Wernicke-Korsakoff complex: a retrospective analysis of 131 cases diagnosed at necropsy. J Neurol Neurosurg Psychiatry 1986, 46: 341-345.

10. De Wardener, H.E. \& Lennox, B. Cerebral beriberi (Wernicke's encephalopathy). Review of 52 cases in a Singapore prisoner-of-war hospital. Lancet 1947, i: 11-17.

11. Cogan, D.G. \& Victor, M. Ocular signs of Wernicke's disease. Arch Ophthalmol 1954, 51: 204.

12. Victor, M., Adams, R.D. \& Collins, G.H. The WernickeKorsakoff Syndrome. A clinical and pathological study of 245 patients, 82 with post-mortem examinations. Davis, Philadelphia, 1971.

13. Ropper, A.H. \& Marmarou, A. Mechanisms of pseudotumour in Guillain-Barré syndrome. Arch Neurol 1984, 41: 259-261.

14. Anonymous. Pathogenesis of optic disc swelling. Editorial. Br J Ophthalmol 1978, 62: 579-580.

15. Adams, R.D. \& Victor, M. Principles of Neurology, 3rd edition. McGraw-Hill, New York, 1985, pp. 187.

16. McLaren, D.S. Nutritional Ophthalmology. (2nd edition of Malnutrition and the Eye). Academic Press, London, 1980 , pp. $150-179$. 